Article

\title{
Study of Polyaniline/Poly(Sodium 4-Styrenesulfonate) Composite Deposits Using an Electrochemical Quartz Crystal Microbalance for the Modification of a Commercial Anion Exchange Membrane
}

\author{
Antonio Montes-Rojas *, Marlen Ramírez-Orizaga, Jesús Gerardo Ávila-Rodríguez and \\ Luz María Torres-Rodríguez \\ Laboratorio de Electroquímica, Facultad de Ciencias Químicas, Universidad Autónoma de San Luis Potosí, \\ Av. Dr. Manuel Nava, Zona Universitaria, San Luis Potosí CP. 78210, Mexico; marlenram@gmail.com (M.R.-O.); \\ avila_rdz@hotmail.com (J.G.Á.-R.); luzmaria@uaslp.mx (L.M.T.-R.) \\ * Correspondence: antonio.montes@uaslp.mx
}

Received: 3 November 2020; Accepted: 24 November 2020; Published: 30 November 2020

\begin{abstract}
One of the intended applications for the modification of ion exchange membranes with polyaniline (PAni) is to use it as a matrix to include chemical species that confer a special property such as resistance to fouling or ion selectivity. In particular, the inclusion of polyelectrolyte molecules into the PAni matrix appears to be the way to modulate these properties of selective membranes. Therefore, it must be clearly understood how the polyelectrolyte is incorporated into the matrix of polyaniline. Among the results obtained in this paper using poly(sodium 4-styrenesulfonate) (PSS) and an electrochemical quartz crystal microbalance, the amount of polyelectrolyte incorporated into PAni is found to be proportional to the PSS concentration in solution if its value is between 0 and $20 \mathrm{mM}$, while it reaches a maximum value when the PSS in solution is greater than $20 \mathrm{mM}$. When the anion exchange membranes are modified with these composite deposits, the transport number of chloride was found to decrease progressively (when the PSS concentration in solution is between 0 and $20 \mathrm{mM}$ ) to reach a practically constant value when a concentration of PSS greater than $20 \mathrm{mM}$ was used.
\end{abstract}

Keywords: poly(sodium 4-styrenesulfonate); polyaniline; anion exchange membrane; electrochemical quartz crystal microbalance

\section{Introduction}

Among the most important characteristics that ion exchange membranes must have, for a successful application, are adequate selectivity and/or resistance to biofueling, for example, for ions of similar charge and size or for bacteria to be present in the solution [1]. In the literature, several different approaches exist to handle these disadvantages that are a feature of membranes [1-6]. For example, one approach is to produce a novel membrane with suitable selective properties; however, this is a complex multistep process [7-9]. Another approach consists of modifying a characteristic of a commercial membrane [4-6]. This method is less expensive, since the membranes conserve most of their transport properties and only the properties related to selectivity or resistance to fouling change.

For this last approach, there have been several reports on the modification of ion exchange membranes using polyaniline. Polyaniline (PAni) is considered to be the most promising material modifier due to its excellent properties, easy synthesis, low cost of the monomer, and high mechanical and thermal stability as compared to other conducting polymers $[10,11]$. 
Some studies have reported that the membranes might be modified superficially by PAni $[12,13]$ or with impregnations or intercalations on the walls of their microchannels [14-19]. In both cases, the PAni generates special transport properties at ion exchange membranes that are completely understood.

For example, Compañ et al. and Berezina et al. [16,19] studied cationic heterogeneous membranes modified with polyaniline intercalations and concluded that the doping of polyaniline macromolecules imparts electrical heterogeneity to the membrane surface, which is due to the development of a microrelief. This microrelief may affect the coupled effects of concentration polarization and optimizes the structure and properties of composite membranes.

In another case, a superficial film of PAni on the membrane was found to work as a positive barrier that repels positive ions and improves its selectivity. For example, it was found $[12,13,19,20]$ that these composite membranes have lower values of electroosmotic permeability as compared to those of the initial membrane.

Despite the importance of the effects of these modifications to polyaniline on the ion exchange membranes, another possibility is that the polyaniline deposited in the membrane functions as a matrix that includes chemical species that confer some special property such as resistance to fouling or selectivity improvements. Regarding the latter, if it is considered that the interactions between ionic species and the superficial layer or the doped PAni enhances the selectivity, then the strength of these interactions can be used to moderate the selectivity of the composite membrane. In our laboratory, we have proposed an approach to control the strength of the ion-PAni interactions on an ion exchange membrane: To deposit on the membrane, a layer or impregnations of PAni with inclusions of a polyelectrolyte such as sodium polystyrene sulfonate are used. Due to the long chain lengths of the polyelectrolytes, they are trapped inside the conducting polymer film, leading to the formation of polymer composites. The positive charges introduced into the polymer matrix during oxidation of the conducting polymer are usually counterbalanced by the anions present in the molecule of polyelectrolyte. In the literature, there are many articles on this issue that have tried to understand these composites using a metallic electrode [21-23] such as gold, but they have not been used to modify a membrane.

For this approach, it is necessary to rigorously control diverse parameters such as the morphology and redox state of polyaniline and the amount of polyelectrolyte included. These characteristics of the PAni composite can be controlled using an electrochemical method in their preparation, because these methods are simple and easy to implement. In addition, they consist of only a few stages. In accordance with the literature, when using metallic electrodes, the role of the polyelectrolyte (PE) in composite deposits is to neutralize the charge of PAni due to doping. This charge compensation process involves the molecules of PE aligning opposite to charges of PAni [24,25]. On the other hand, the literature has [26-28] reported that the PE affects the morphology and the amount of PAni deposited onto the electrode.

Importantly, a valuable tool in this regard is the electrochemical quartz crystal microbalance (EQCM). The principle of EQCM and several examples of its use are summarized in references [29] and [30]. In the field of conducting polymers, the EQCM was introduced by Orata and Buttry [31], who showed that the doping process and the redox state of PAni are strongly related. Thus, the deprotonation of amine groups in the PAni (leucoemeraldine base) occurs during its oxidation (electron loss), which produces the imine group (emeraldine base and pernigraniline base). These forms can in turn be protonated, and thus charged sites were formed in the material. To maintain the electroneutrality of the PAni, anions of small molecular sizes are usually exchanged with the solution during the doping-dedoping processes of the conducting polymer. Specifically, the variation in the mass involved with the exchange of ions was detected by EQCM.

More recently, Ding and Park [32] studied the incorporation of PSS (poly(sodium 4-styrenesulfonate)) into a deposit of PAni using the EQCM. They also analyzed the electropolymerization of aniline onto a gold electrode with and without PSS in solution. Their results showed that in both cases, the charge associated with PAni was the same, but the mass detected by EQCM was higher when PSS was in 
solution. This result is contrary to the conclusions of Hyodo et al. [25] because they found that the addition of PSS accelerated the growth rate of PAni. In addition, these researchers found that the PAni/PSS composite that formed had dominantly anion-exchanging characteristics. This property dominates at lower $\mathrm{pH}$ values, and its contribution decreases with an increase in the $\mathrm{pH}$. This result is surprising and is not in agreement with what has been generally believed for this type of composite polymer [33-35].

However, it is not possible to find research with similar results related to this property of PAni/PSS composites. Only Pile et al. [36] analyzed the effect of oxidation state on the permeability of several probe molecules through conducting polymer membranes comprised of PAni composites in a PAni/PSS aqueous solution. For example, they found that the permeability of the reduced state of composite is very similar to that observed for the pure PAni film compared to the oxidized state. This behavior reflects the competition between the nature of the reduced film, which is more compact but is a pure cation exchanger with a fixed PSS charge, and the oxidized film, which is swollen but is not a pure cation exchanger, since it contains both negative charges from bound PSS and positive charges from the charge injected during oxidation.

Despite this information regarding the properties of PAni/PSS composites, their effect on the properties of a commercial membrane has not yet been studied. In addition, it is not even known what effect the amount of PSS has on PAni electropolymerization.

Considering the aforementioned, the effect of different amounts of polyelectrolyte on electropolymerization of PAni using an EQCM was analyzed for the first time in this study. Afterwards, the results obtained for the first step were extended to modification of a commercial anion exchange membrane with PAni/PSS composites.

\section{Materials and Methods}

\subsection{Electromicrogravimetric Study of the PAni/PSS Composite Deposits}

\subsubsection{Materials}

The solutions used in this work were prepared with deionized water, with a resistivity of $18 \mathrm{M} \Omega \mathrm{cm}$ obtained from a Mili-Q Reference Ultrapure Water Purification System, and aniline of reagent grade (Sigma-Aldrich, Saint Louis, MO, USA) and doubly distilled. The polyelectrolyte poly(sodium 4-styrenesulfonate) (PSS, Mw 70000, Acros Organics, Bridgewater, NJ, USA) was used as received.

The working solution had $0.1 \mathrm{M} \mathrm{H}_{2} \mathrm{SO}_{4}$ and $0.10 \mathrm{M}$ aniline with PSS 2.5-40 mM. The electropolymerization of composite deposits was performed using 40 cyclic voltammetry scans with the interval potential limited by $-100 \mathrm{mV}$ and $+1000 \mathrm{mV}$. The scan rate used was $50 \mathrm{mV} \mathrm{s}^{-1}$.

Finally, a $0.5 \mathrm{M}$ solution of camphorsulfonic acid (HCS, Sigma-Aldrich, Saint Louis, MO, USA) was used to study the charge compensation process of the composites by using EQCM.

\subsubsection{Experimental Setup}

All EQCM measurements were performed with a made-home electrochemical cell to facilitate the replacement of the resonators. An AT-cut, $9 \mathrm{MHz}$ gold-plated quartz crystal (Seiko EG\&G Au, Seiko EG\&G Co., Ltd., Tokyo, Japan, $0.196 \mathrm{~cm}^{2}$ ) mirror finish was used as a resonator and an electrode. A platinum wire functioned as an auxiliary electrode and an $\mathrm{Ag} / \mathrm{AgCl} / 3 \mathrm{M} \mathrm{KCl}$ cell was employed as the reference electrode. Both electrodes were contained in a glass extension that only contained an acidic solution $\left(0.1 \mathrm{M} \mathrm{H}_{2} \mathrm{SO}_{4}\right)$ without aniline.

Both the quartz-crystal analyzer and potentiostat/galvanostat were obtained from Princeton Applied Research; the first was a Seiko EG\&G model 917 and the second was an EG\&G model 273A. The data acquisition was carried out using the software WinEchem 1.5 (Seiko EG\&G Co., Ltd., Tokyo, Japan) from the same provider. A schematic representation of the experimental setup with the main components used in this determination is shown in Scheme 1. 
(3)

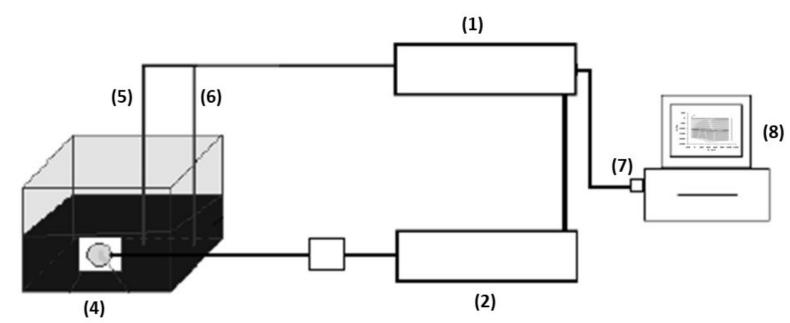

Scheme 1. Experimental setup: (1) Potentiostat, (2) QCM, (3) made-home electrochemical cell, (4) $9 \mathrm{MHz}$ gold-plated quartz crystal, (5) auxiliary electrode, (6) reference electrode, (7) controller card and (8) personal computer.

\subsubsection{Characterization of the PAni/PSS Composite Films Using Scanning Electron Microscopy}

Micrographs of the PAni/PSS composite films were obtained using Scanning Electron Microscopy (SEM), and the percentage of sulfur content (\%S) by Energy Dispersive $X$ ray (EDX) was also obtained. These analyses were performed with a QUANTA 200 FEI microscope (Thermo Fisher Scientific, Bridgewater, NJ, USA).

The handling of the samples was as follows: the quartz electrodes used to prepare the PAni/PSS composite deposits were placed directly on the sample holder. They were then placed under the electron beam to make the determinations.

\subsection{Modification of the Commercial Anion Exchange Membrane}

\subsubsection{The Commercial Membrane}

The commercial anion exchange membrane was provided by Tokuyama Soda Co. Ltd. Tokio, Japan. This membrane is denominated as AFN and is a homogeneous membrane with $\mathrm{NR}_{3}{ }^{+}$groups according to the manufacturer. Some characteristic properties of the AFN membrane are reported in Table 1.

Table 1. Some characteristics of the commercial anion exchange membrane AFN $[37,38]$.

\begin{tabular}{cc}
\hline Parameter & Value \\
\hline Type & Permeable at anions, strongly basic \\
Electric resistance $\left(\Omega \mathrm{cm}^{2}\right)$ & $0.4-1.5$ \\
Thickness $(\mu \mathrm{m})$ & 160 \\
Ionic exchange capacity $\left(\mathrm{meq} \mathrm{g}^{-1}\right)$ & $2.0-3.5$ \\
Water uptake $\left(\mathrm{g} \mathrm{H}_{2} \mathrm{O} \mathrm{g}^{-1}\right)$ & $0.40-0.55$ \\
Specifications & Resistance to fouling by organic particles \\
\hline
\end{tabular}

\subsubsection{Procedure for the Modification of Membranes}

A carbon paste electrode was used as a support to adhere to the samples of the commercial membrane and proceed to their modification by using cyclic voltammetry, as described elsewhere [39]. Membrane discs with an area of $4.9 \mathrm{~cm}^{2}$ were used in this work. To remove any impurities in the membrane, the disc was treated as follows: initially, the membranes were immersed in $1 \mathrm{M} \mathrm{HNO}_{3}$ for at least $24 \mathrm{~h}$ with moderate agitation. Subsequently, the membranes were rinsed thoroughly using an ultrasound bath and Milli-Q water to remove any trace of nitric acid. Finally, the membranes were kept in $1 \mathrm{M} \mathrm{H}_{2} \mathrm{SO}_{4}$ for $24 \mathrm{~h}$ or longer until they were used. 


\subsection{Characterization of the Modified Membranes}

\subsubsection{Electrochemical Characterization of Modified Membranes}

After the membranes were modified with the different types of PAni/PSS composite deposits, each of them was reattached to the electrode and their voltammetric responses were then obtained using an aniline-free sulfuric acid solution.

\subsubsection{Determination of the Transport Numbers Using the Modified Membranes}

The characterization of the modified membranes included the determination of the counterion transport number, $t_{a}$, which was measured using the concentration cell method developed by Ltief et al. [40]. This method consists of using reference electrodes to measure the membrane potential $\left(E_{m}\right)$ generated when the membrane separates two solutions with different chemical activities.

The experimental setup used in this determination involved placing the membrane (with an exposed area to solutions of $0.7853 \mathrm{~cm}^{2}$ ) between two symmetric glass beakers connected with a $1 \mathrm{~cm}$ length and $1 \mathrm{~cm}$ internal diameter tube. Two $\mathrm{Ag}|\mathrm{AgCl}| \mathrm{NaCl}(3 \mathrm{M})$ reference electrodes were used to measure $\mathrm{E}_{\mathrm{m}}$. Each electrode was placed inside a glass extension filled with $3 \mathrm{M} \mathrm{NaCl}$. The top of the glass extension was blocked with an agar plug $(3 \% w / w)$, which prevented loss of the $\mathrm{NaCl}$ solution and established the ionic contact. The membrane potential was measured every $10 \mathrm{~s}$ for 15 min with a UNI-T UT70C multimeter, which was connected to a computer by a R232 port and was controlled through the UT70C software, provided by the supplier. The experiments were performed under constant agitation, and the initial and final temperatures were recorded in each experiment. Furthermore, each experiment was performed at least three times.

For determination of the counterion transport number at a concentration of $0.01 \mathrm{M}$, it was employed a set of four solutions of different concentrations (namely, two higher and two lower concentrations); the counterion transport number was determined from the measured membrane potential according to the following equation:

$$
E_{m}=\left(2 t_{a}+1\right) \frac{R T}{z F} \ln \frac{a_{1}}{a_{2}}
$$

where $a_{1}$ is the activity of the constant concentration solution, and $a_{2}$ is the activity of the concentration variable solution. It should be noted that these values were determined using the Guntelberg equation [41]. In addition, $R$ represents the gas constant $\left(8.314 \mathrm{~J} \mathrm{~mol}^{-1} \mathrm{~K}^{-1}\right)$, and $T$ represents the temperature $(\mathrm{K})$, while $z$ and $F$ represent the counterion charge and the Faraday constant $\left(96,500 \mathrm{C} \mathrm{mol}^{-1}\right)$, respectively.

Finally, when working with the modified membranes, special care was taken to ensure that the modified side of the membrane was in contact with the higher concentration solution.

\section{Results}

\subsection{Potentiodynamic Behavior of the PAni/PSS Composites on the Gold Electrode}

The cyclic voltammograms recorded in sulfuric acid with the PAni/PSS composites obtained with different concentrations of PSS during their preparation are shown in Figure 1a. All the curves show two redox pairs with two oxidation peaks at approximately $300 \mathrm{mV}$ and $700 \mathrm{mV}$ and two reduction peaks at $0 \mathrm{mV}$ and $450 \mathrm{mV}$. These characteristics correspond to the typical footprint of PAni in an acid medium $[42,43]$, but do not correspond to that of the polyelectrolyte, since it is not electroactive. 

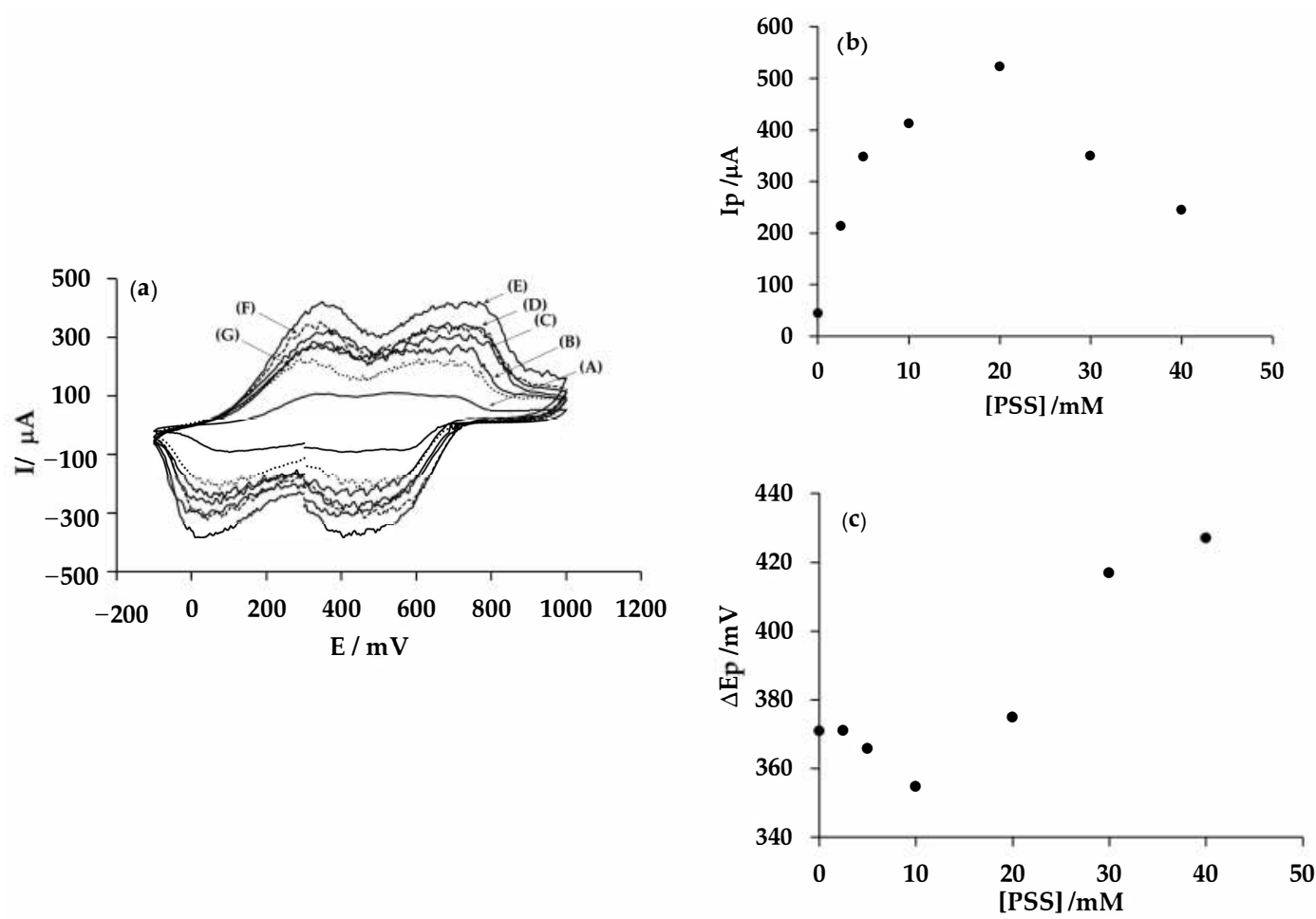

Figure 1. Plot (a) shows cyclic voltammograms of the PAni/poly(sodium 4-styrene sulfonate) (PSS) composite recorded at $50 \mathrm{mV} \mathrm{s}^{-1}$ in $0.5 \mathrm{M} \mathrm{H}_{2} \mathrm{SO}_{4}$ without aniline that were prepared with different PSS concentrations: (A) 0, (A) 2.5, (C) 5, (D) 10, (E) 20, (F) 30, and (G) $40 \mathrm{mM}$. Plot (b) shows the anodic current peaks, $\mathrm{I}_{\mathrm{p}}$, localized around $400 \mathrm{mV}$, and plot (c) shows the difference of potential between the anodic peaks, $\Delta \mathrm{E}_{\mathrm{p}}$, in a function of the PSS concentration.

According to different studies [42-45], the peaks mentioned above are attributed to redox processes of PAni that involve two stages of charge transfer. In the first, at $300 \mathrm{mV}$, the transformation of leucoemeraldine to the protonated emeraldine form occurs. The second stage, at $700 \mathrm{mV}$, involved the incomplete transformation of emeraldine to pernigraniline.

Further analysis shows that the peak potential is shifted towards high potential only for the oxidation peak at $700 \mathrm{mV}$ with an increasing concentration of PSS, while for the other peaks, the increasing the concentration of PSS does not influence the position of their peak potentials. In addition, when the PSS concentration is less than $20 \mathrm{mM}$, the detected current increases proportionally with the increasing PSS concentration (curves B-E). This implies that increasing the concentration of polyelectrolyte present during the electropolymerization of PAni catalyzes its polymerization, which implies that the addition of PSS accelerated the growth rate on the gold electrode. Some studies $[25,32]$ have shown that large amounts of PSS molecules are adsorbed on the positively polarized surface of the gold electrode during the first cycle of electropolymerization and may also retain small dimeric and oligomeric species. The PSS molecules adsorbed on the positively charged electrode surface may now act as a template for the polymerization of aniline, which not only helps accumulate weight quickly on the electrode surface but also facilitates the electron-transfer reaction across the polymer film. Likewise, it was observed that the peak current $\left(I_{p}\right)$, Figure $1 b$, such as the oxidation peak at $350 \mathrm{mV}$, increases with an increasing PSS concentration (curves B-E). Indeed, the current increases from $100 \mu \mathrm{A}$ to $400 \mu \mathrm{A}$ with an increasing PSS concentration. However, if the PSS concentration is above $20 \mathrm{mM}$ (curves F and G), then the peak current decreases with an increasing PSS concentration. This behavior is best appreciated by examining Figure $1 \mathrm{~b}$.

Another parameter analyzed from voltammograms was the difference of potential between the anodic peaks, $\Delta \mathrm{E}_{\mathrm{p}}$. Indeed, the separation between anodic peaks tends to decrease with the addition of sulfonic groups to PAni. The corresponding values obtained for $\Delta \mathrm{E}_{\mathrm{p}}$ for each PSS concentration 
are shown in Figure 1c. Accordingly, $\Delta \mathrm{E}_{\mathrm{p}}$ decreases when the PSS concentration increases between 0 and $10 \mathrm{mM}$ (curves B-D). Thus, the increasing incorporation of PSS into the PAni deposit decreases $\triangle \mathrm{E}_{\mathrm{p}}$ if the PSS concentration is between 0 and $10 \mathrm{mM}$. At a PSS concentration greater than $10 \mathrm{mM}$ (curves E-G), the opposite effect is observed, i.e., an increase in PSS concentration leads to an increase in the $\Delta \mathrm{E}_{\mathrm{p}}$ value. This indicates that a maximum amount of PSS incorporates into the PAni matrix. Importantly, the behavior of $\Delta \mathrm{E}_{\mathrm{p}}$ is similar to the behavior of $\mathrm{I}_{\mathrm{p}}$, since in both cases, an increase in the PSS concentration in solution leads to increases in the incorporation of PSS into the PAni matrix. However, if the concentration continues to increase, then there is less incorporation.

\subsection{Electromicrogravimetric Behavior of PAni/PSS Composites on a Gold Electrode}

During the electrochemical synthesis of PAni/PSS composites, the change in frequency $\left(\Delta \mathrm{f}=\mathrm{f}-\mathrm{f}_{\mathrm{O}}\right.$ in $\mathrm{Hz}$ ) was measured, which was transformed into mass change $(\Delta \mathrm{m})$ per surface unit by employing Sauerbrey's equation:

$$
\Delta \mathrm{f}=-\frac{\mathrm{f}_{\mathrm{o}}{ }^{2}}{\mathrm{~N} \rho_{\mathrm{q}}} \Delta \mathrm{m}
$$

where the following terms are constant: $f_{o}$ (fundamental frequency, Hz), $\rho_{q}$ (quartz density), and $N$ (constant related to the speed of the acoustic wave traveling through the quartz). These terms can be grouped in a constant named the sensitivity factor $\left(C_{f}\right)$ that is obtained by calibration, for example with silver, copper, or thallium [46-48].

According to this equation, the mass change can be obtained from the frequency change if $C_{f}$ is known. The minus sign in this equation indicates that a decrease in the frequency implies an increase in the mass.

Figure 2 shows the frequency change recorded during the electrochemical synthesis of PAni films without polyelectrolyte in the work solution.

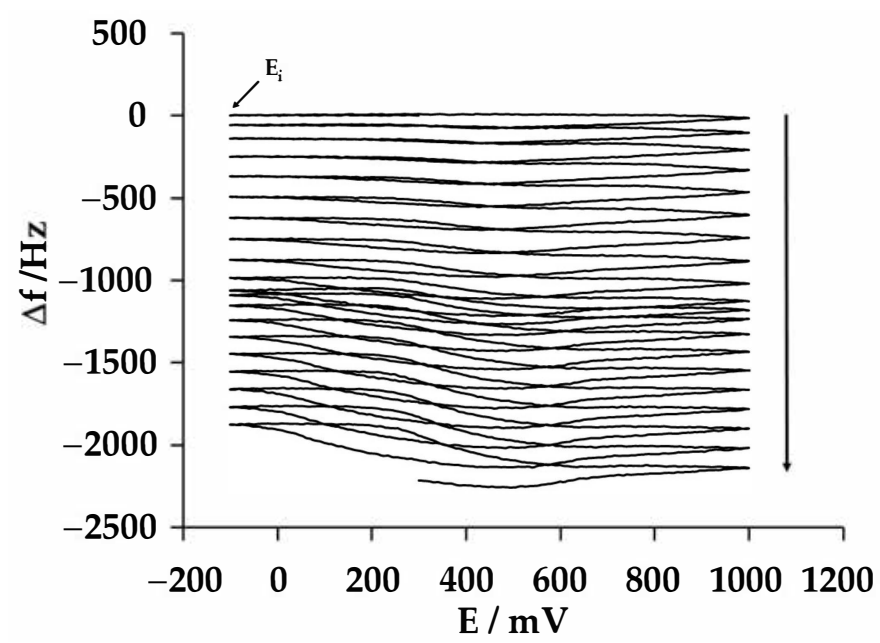

Figure 2. Curve of the frequency shifts $(\Delta \mathrm{f})$ as a function of the potential (E) obtained during the electrodeposition of pure PAni onto the gold electrode in the work solution at $50 \mathrm{mV} \mathrm{s}^{-1}$.

This result clearly indicates that the tendency of $\Delta \mathrm{f}$ is to decrease when the number of scan cycles increase, which is associated with the progressive growth of the PAni deposit on the gold electrode [32]. Additionally, a careful analysis of this graph shows that the frequency change is related to the doping-dedoping process, such as the decrease in frequency recorded from the last two cycles of potential scan between $-100 \mathrm{mV}$ and $600 \mathrm{mV}$. The same trend was observed in the frequency shift curves recorded during the doping-dedoping process for all PAni/PSS films.

In order to find further information on the effect of PSS concentration on the composite deposition growth, the mass change was obtained from the frequency shift curves recorded during the potentiodynamic polymerization of aniline with and without PSS in the work solution. Figure 3a shows 
the mass $(\Delta \mathrm{m})$ of the PAni/PSS deposits generated as a function of the potential cycle number. From these curves, two important differences could be noted when the polyelectrolyte was added (curves B-G) or not (curve A) to the synthesis solution. The first one is related to the trend data; indeed, in absence of PSS (curve A), the mass values follow a linear trend with the potential cycle number. Meanwhile, in the presence of PSS, all curves (B-G) are not completely linear with a unique slope but exhibit two slopes. This characteristic implies that the growth of composite deposits was affected by the PSS concentration in the synthesis solution, and thus the polyelectrolyte was involved in the polymerization of the aniline.
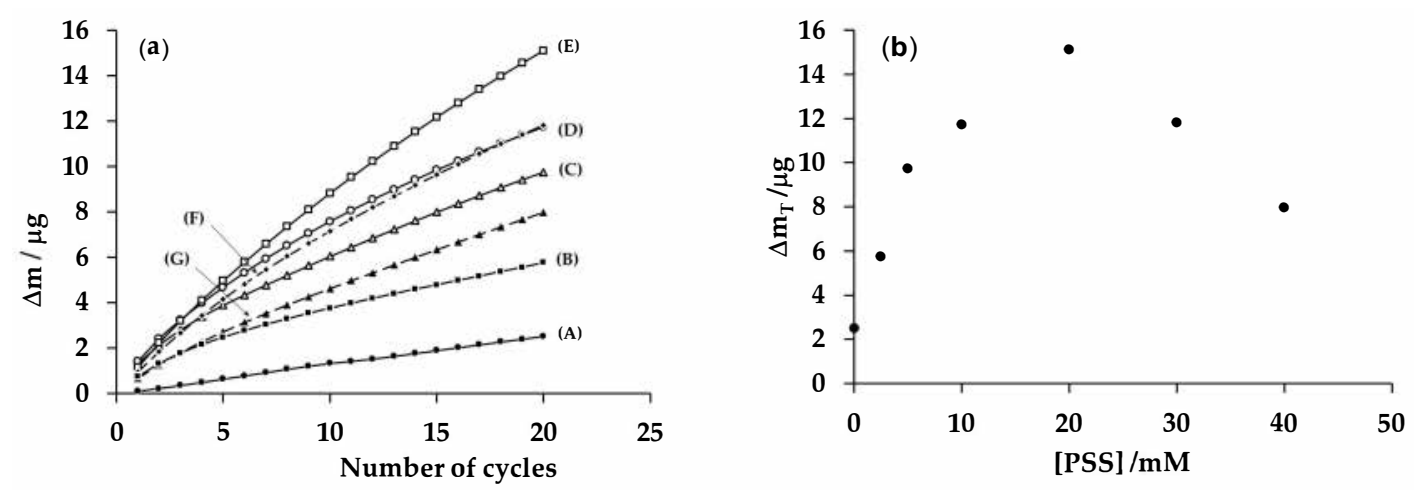

Figure 3. (a) Curves of the mass shifts $(\Delta \mathrm{m})$ as a function of the number of potential sweep cycles, carried out during the electrosynthesis of the PAni/PSS composite deposits at different concentrations of PSS in solution: (A) 0, (B) 2.5, (C) 5, (D) 10, (E) 20, (F) 30 and (G) $40 \mathrm{mM}$. (b) The total mass $\left(\Delta \mathrm{M}_{\mathrm{T}}\right)$ of PAni/PSS composite as a function of the PSS concentration in the work solution.

The second difference is associated with the amount of PAni deposited in presence of different PSS concentrations to the same potential cycle number, since as can be seen from the Figure 3a (for example at 10 or 20 cycles), in presence of PSS, the amount of PAni deposited on the electrode is always higher than in the absence of polyelectrolyte. In addition, $\mathrm{m}$ has different behaviors depending on the PSS concentration.

In order to better appreciate these behaviors, $\Delta \mathrm{m}$ at 20 cycles depending on PSS concentration is shown in Figure 3b. Notably, from this curve, if the PSS concentration is less than $20 \mathrm{mM}$, then the mass change (the amount of PAni deposited on electrode) increases proportionally with the amount of polyelectrolyte used in the synthesis of PAni. In this case, the PSS accelerates the growth rate of PAni, as has been mentioned by several authors [25]. Conversely, if the PSS concentration is greater than $20 \mathrm{mM}$, then the amount of PAni deposited on electrode decreases with the increasing concentration of polyelectrolyte. To explain this behavior, it is necessary to consider the role of the polyelectrolyte molecules.

As has been mentioned in other works [24,25], the polyelectrolyte molecules are adsorbed on the positively polarized surface during the first cycle to obtain polyaniline so that they retain small dimeric and oligomeric species. Because the sulfonate groups lose their proton around $\mathrm{pH}$ 0.5-1.0, the polyelectrolyte molecule has a net electrical charge counterbalanced by counterions existing in the solution. Since the synthesis solution has a $\mathrm{pH}$ near 1 , the polyelectrolyte molecules adopt an extended chain conformation due to the repulsion between sulfonic groups. In these conditions, almost $50 \%$ of the $-\mathrm{SO}_{3} \mathrm{H}^{+}$groups from the added PSS are also in solution, and the neutral molecules have not lost their protons. However, the charged molecules are precisely those that adsorb onto the electrode and accelerate the growth rate, since they prevent small dimeric and oligomeric species from diffusing away from the electrode surface into the solution. Considering this, if the PSS concentration increases, then the charged flexible chains adopt a more compact conformation with loops and tails, due to the slight increase in ionic strength associated with the addition of PSS. These conformations are less effective in preventing the diffusion of the oligomeric species; given that increasing the PSS 
concentration also increases the amount of compact species (consequently decreasing the elongated species), these species decrease the growth rate of PAni.

Additionally, the PAni grows on the adsorbed polyelectrolyte, incorporating into its matrix charged molecules of PSS, meaning the mass difference detected in the presence or absence of PSS is quite important due to its exclusively catalytic effect.

As part of efforts to generate more information on this issue, measurements of the shift frequency were made without polarization (on an open circuit) of the electrode using a solution of $1 \mathrm{M} \mathrm{H}_{2} \mathrm{SO}_{4}$, which was added to $20 \mathrm{mM}$ or $40 \mathrm{mM}$ of PSS. These measurements were performed before and after adding PSS to the acidic solution. Figure 4 shows the obtained results.

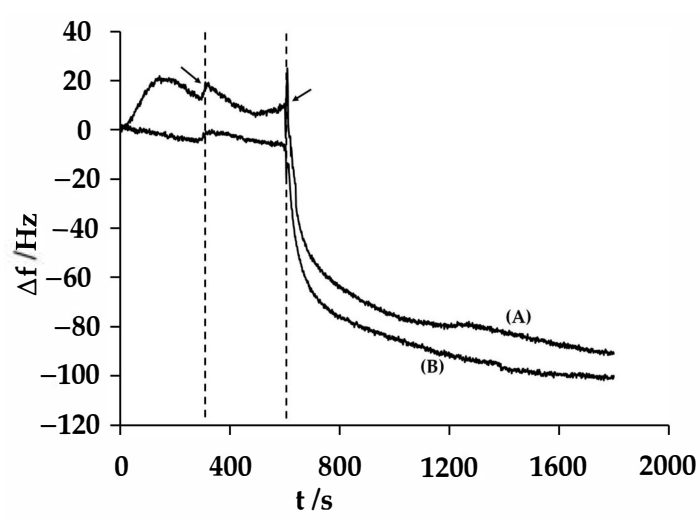

Figure 4. Frequency shifts $(\Delta \mathrm{f})$ recorded during the addition of $1 \mathrm{~mL}$ of the $1 \mathrm{M} \mathrm{H}_{2} \mathrm{SO}_{4}$ solution at $5 \mathrm{~min}$ and $1 \mathrm{~mL}$ of the PSS solution at $10 \mathrm{~min}$, equivalent to a final concentration of polyelectrolyte of (A) 20 and (B) $40 \mathrm{mM}$ in $1 \mathrm{M} \mathrm{H}_{2} \mathrm{SO}_{4}$.

The data obtained show that adding only $1 \mathrm{~mL}$ of $1 \mathrm{M} \mathrm{H}_{2} \mathrm{SO}_{4}$ at 5 min (dashed line) causes the frequency variations to remain almost invariant. However, if a $1 \mathrm{M} \mathrm{H}_{2} \mathrm{SO}_{4}$ solution is added to $20 \mathrm{mM}$ or $40 \mathrm{mM}$ PSS at a time of $10 \mathrm{~min}$ (see arrow), then the frequency change decreases (mass increases) to a practically constant value near $-100 \mathrm{~Hz}$.

This frequency change behavior suggests that the PSS effectively adsorbs on the electrode surface and improves the polymerization of the aniline, as was mentioned above.

\subsection{Electromicrogravimetric Analysis of the Effect of Polyelectrolyte Concentration on the Electrosynthesis of} Composite PAni/PSS Deposits

\section{Analysis of the Mass/Charge Ratio at Different Concentrations of PSS}

With the purpose of better understanding how the PSS concentration affects the polymerization of polyaniline, the mass variation $(\Delta \mathrm{m})$ as a function of charge variation $(\Delta \mathrm{Q})$ was determined from the cyclic voltammograms and frequency shifts simultaneously recorded during the growth of polyaniline on the Au electrode, as shown in Figure 5.

As can be seen, the curve obtained in the absence of PSS (curve A in Figure 5a) shows a linear behavior, which implies that the mass recorded is directly proportional to the electroactive species deposited on the electrode. However, if the polyaniline was synthesized in the presence of PSS, then the curves (curves B-G) showed an inflection point that divides the curve into two segments with different slopes: At the start of the polymerization, for example in curve $B$, the segment is linear with a slope of $0.3 \mu \mathrm{g} \mathrm{mC}^{-1}$, but when the electrosynthesis advances the slope of the segment becomes lower. This last situation suggests that PSS incorporation into the PAni film decreases as the PAni deposit thickens. 

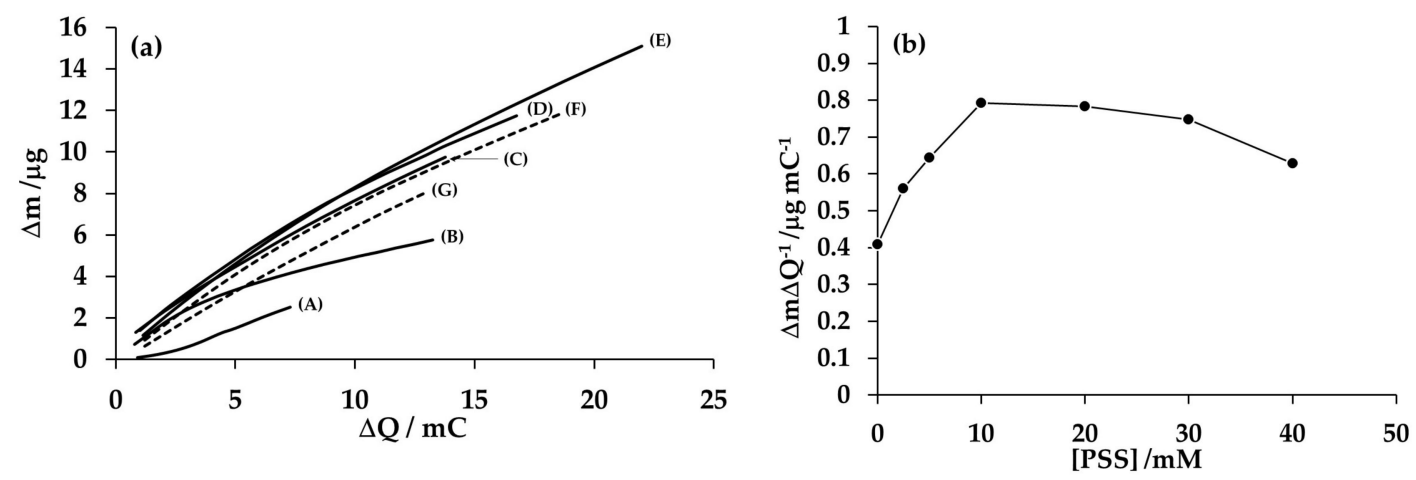

Figure 5. (a) Mass shifts $(\Delta \mathrm{m})$ as a function of change in charge $(\Delta \mathrm{Q}$ or $\mathrm{Q})$ and (b) slope $(\Delta \mathrm{m} / \Delta \mathrm{Q})$ of the initial stage of during the growth of PAni versus PSS concentration calculated from the cyclic voltammograms during the growth of PAni films with different PSS concentrations as follows: (A) 0, (B) 2.5, (C) 5, (D) 10, (E) 20, (F) 30, and (G) $40 \mathrm{mM}$.

The result is consistent with other reports [3] in which it was shown that as the thickness of PAni deposits increases, the amount of polyelectrolyte decreases. The electrostatic interactions exerted between polyelectrolytes chains could possibly affect the incorporation of PSS into PAni deposit.

Figure $5 b$ shows the slope of the curves at the start of the polymerization as a function of PSS concentration in the work solution. The curve shows that the slope and PSS concentration increase proportionally at low PSS concentrations. If PSS concentration is between 10 and $20 \mathrm{~mm}$, then the slope reaches a maximum value. Finally, when the PSS concentration is greater than $20 \mathrm{mM}$, then the slope decreases. This behavior of the slope suggests that when the concentration of polyelectrolyte in solution is low (down to about $20 \mathrm{mM}$ ), the quantity of PSS incorporated into the PAni deposits is directly proportional to its concentration in solution. In addition, if the PSS concentration in solution is greater than $20 \mathrm{mM}$, then the PSS incorporation into the PAni deposit is indirectly proportional to its concentration in solution. The origin of these results is still unclear, but could be related to a limitation on the amount of PSS that can be incorporated into the PAni deposits while the amount of PAni increases. Notably, a similar trend was reported in other studies [10] in which the incorporation of PSS into the PAni/PSS system was evaluated by infrared, but the authors did not explain their results.

\subsection{Study of the Charge Compensation Process of the Composites}

The evaluation of the charge compensation process for each of the PAni/PSS deposits prepared can provide information about how the polyelectrolyte is incorporated into the PAni deposit at different PSS concentrations in the work solution. The charge compensation process of a conductive polymer is a phenomenon that involves different chemical forms of the polymer that differ in their electronic, electrical, magnetic, optical, and structural properties. For example, when the polymer is partially oxidized by electrochemical anodic oxidation, then the removal of electrons from the backbone of the polymer is accompanied by a delocalization of positive charge across its entire polymeric chain (backbone $\pi$ system). In this process, counter ions are introduced from solution, which stabilize (compensate) the charge on the polymer backbone. If the polymer is reduced, then the positive charge disappears, the polymer returns to its neutral state, and the counter ions leave the polymer. Since this process is similar to that present in semiconductors, it is also known as the "doping/dedoping process" and the counter ions as the "dopant". Doping is a reversible process so that the original polymer can be reproduced with little or no degradation of the polymer backbone. Both the doping and dedoping processes involve dopant counter ions that stabilize the doped state.

When the compensation charge process of a doped polymer is followed by EQCM, then the mass of polymer increases due to the entry of counter ions into the polymer from solution. However, if the doped polymer passes to the dedoped state the mass decreases because the counter ions are expelled from the polymer. 
If by some means the dopant ion already exists in the polymer before the doping/dedoping process, then the process of mass gain and loss can be used, in this case, to initiate the incorporation of PSS into PAni deposit.

In order to analyze the doping/dedoping process of the PAni/PSS composites, they were used in two $0.5 \mathrm{M}$ acid solutions with anions of different sizes: sulfuric acid, $\mathrm{H}_{2} \mathrm{SO}_{4}$, and camphor sulfonic acid (HCS) with molar masses of 97.1 and $231.3 \mathrm{~g} \mathrm{~mol}^{-1}$, respectively. The doping/dedoping process was studied by using cyclic voltammetry coupled to an EQCM, and the potential was swept between -100 and $1000 \mathrm{mV}$ using a scan rate of $50 \mathrm{mV} \mathrm{s}^{-1}$.

Figure 6 shows only the voltammograms and frequency shifts concurrently recorded with CVs during the doping/dedoping process for the PAni/PSS composites using the PSS concentration 0, 20, and $40 \mathrm{mM}$ in $0.5 \mathrm{M} \mathrm{H}_{2} \mathrm{SO}_{4}$ and $\mathrm{HCS} 0.5 \mathrm{M}$.
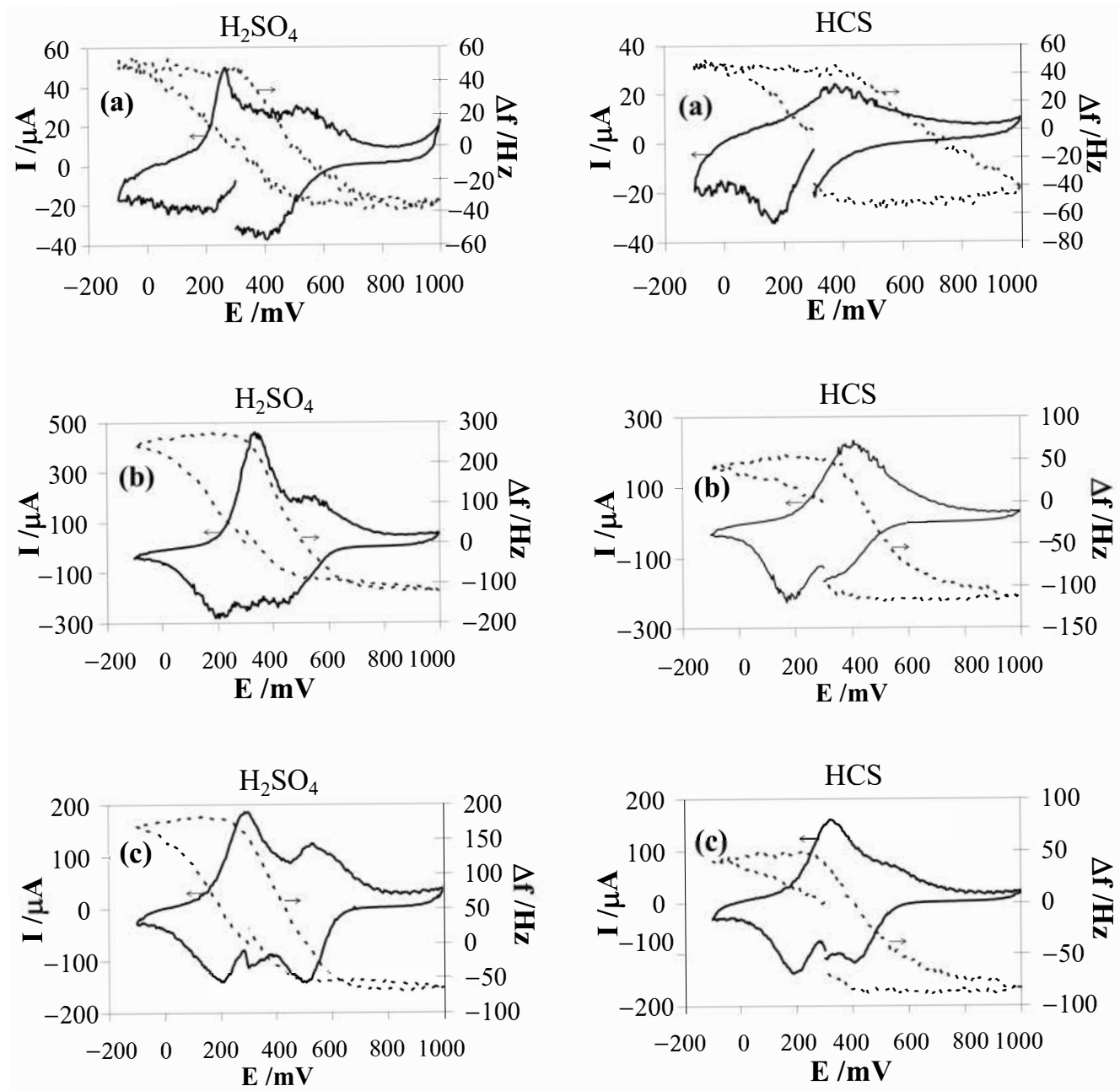

Figure 6. Voltammograms and frequency shifts concurrently recorded with CVs during the doping/ dedoping process for PAni and PAni/PSS composites in $0.5 \mathrm{M} \mathrm{H}_{2} \mathrm{SO}_{4}$ and HCS. In both type of curves, PSS concentrations of (a) 0, (b) 20 and (c) $40 \mathrm{mM}$ were used. The scan rate was $50 \mathrm{mV} / \mathrm{s}$.

The potentiodynamic curves (I-E) have the same characteristics mentioned in the paragraphs above and shown in Figure 1. As for the frequency shifts curves, all the responses show the same general form, i.e., the frequency shifts adopt a constant value in a specific potential range, at the beginning and end of the cycle, where no process occurs. While in the middle of the cycle, the frequency shifts adopt different values. For example, as shown in Figure $6 \mathrm{~b}$, when $\mathrm{H}_{2} \mathrm{SO}_{4}$ was used, the frequency reached a constant value of about $-100 \mathrm{~Hz}$ between $600 \mathrm{mV}$ and $1000 \mathrm{mV}$ and reached about $250 \mathrm{~Hz}$ between $300 \mathrm{mV}$ and $-100 \mathrm{mV}$. This evolution of frequency shift is associated with the doping-dedoping 
process, which involves the anions of the solution and the charges of the polyelectrolyte present in the PAni deposit. When the PAni is oxidized, positive charges are introduced into the polymer matrix, and as a result, anions must necessarily migrate from the solution to neutralize the excess positive change. Consequently, the frequency shifts decreases from $250 \mathrm{~Hz}$ to $-100 \mathrm{~Hz}$ (the total frequency shift, $\Delta \mathrm{f}\left(\mathrm{H}_{2} \mathrm{SO}_{4}\right)$, is almost $\left.350 \mathrm{~Hz}\right)$. Importantly, in this process, the charges of the incorporated polyelectrolyte are also involved. In this way, both the anions and the polyelectrolyte neutralize the excess positive change injected into the polymer. In the case where HCS is used, the role of the polyelectrolyte in neutralizing the excess positive charge is more important because the large acid anion cannot enter the matrix. In this case, the frequency shifts decrease from $50 \mathrm{~Hz}$ to $16-110 \mathrm{~Hz}$ (almost $\Delta \mathrm{f}(\mathrm{HCS})=160 \mathrm{~Hz}$ ). Interestingly, the remarkable hysteresis between the frequency shifts is associated with the incorporation of counterions and their rejection from the matrix, which involves the large anion size of HCS.

According to the results obtained using $\mathrm{H}_{2} \mathrm{SO}_{4}$, the total frequency shifts values when using $\mathrm{H}_{2} \mathrm{SO}_{4}$ are always superior to those obtained using HCS, although the HCS anion is heavier than that of $\mathrm{H}_{2} \mathrm{SO}_{4}$, which means that in this electrolytic medium the anion plays a more important role in neutralizing the excess positive charges in the PAni than when using HCS. These results also indicate that the incorporated PSS plays a more important role in neutralizing the excess positive charges in the polymer than the ions coming from the solution, when HCS is used.

With the purpose of evaluating the relationship between the total frequency shifts obtained with the two anions, $\Delta \mathrm{f}\left(\mathrm{H}_{2} \mathrm{SO}_{4}\right)$ and $\Delta \mathrm{f}(\mathrm{HCS})$, a curve was prepared with $\Delta \mathrm{f}\left(\mathrm{H}_{2} \mathrm{SO}_{4}\right) / \Delta \mathrm{f}(\mathrm{HCS})$ as a function of the PSS concentration, as shown in Figure 7.

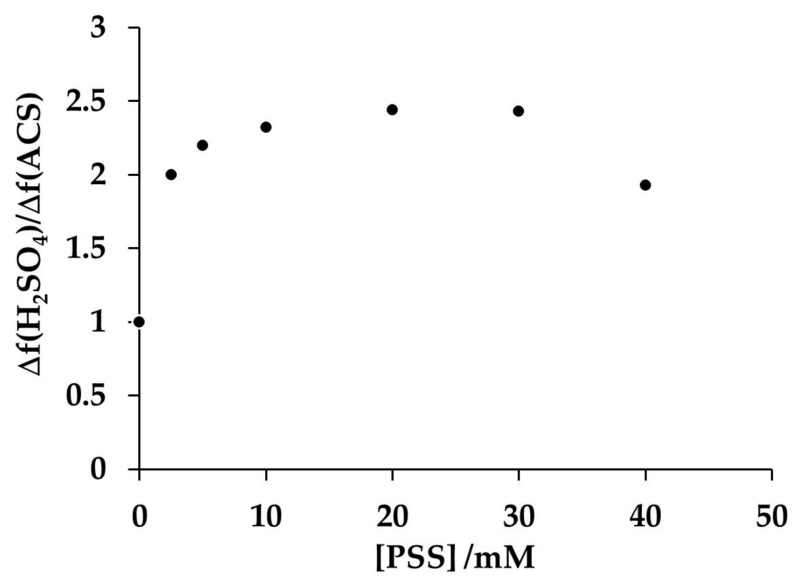

Figure 7. Effect of the PSS concentration in the work solution on the ratio of the total frequency shift using $\mathrm{H}_{2} \mathrm{SO}_{4}$ and $\mathrm{HCS}, \Delta \mathrm{f}\left(\mathrm{H}_{2} \mathrm{SO}_{4}\right) / \Delta \mathrm{f}(\mathrm{HCS})$, which were obtained from Figure 6.

According to these data, if the PSS concentration is less than $20 \mathrm{mM}$, then $\triangle \mathrm{f}(\mathrm{HCS})$ is almost half of $\Delta \mathrm{f}\left(\mathrm{H}_{2} \mathrm{SO}_{4}\right)$ and $\Delta \mathrm{f}\left(\mathrm{H}_{2} \mathrm{SO}_{4}\right) / \Delta \mathrm{f}(\mathrm{HCS})$ is between 2 and 2.5. This implies that when the PSS concentration increases in the synthesis solution, more PSS is incorporated in the matrix of PAni and less of the HCS anion participates in the doping process. On the contrary, if the PSS concentration in the work solution is greater than $20 \mathrm{mM}, \Delta \mathrm{f}(\mathrm{HCS})$ increases and $\Delta \mathrm{f}\left(\mathrm{H}_{2} \mathrm{SO}_{4}\right) / \Delta \mathrm{f}(\mathrm{HCS})$ decreases from 2.5 to 2 . This implies that when the PSS concentration is greater than $20 \mathrm{mM}$ in the synthesis solution, less PSS is incorporated into the PAni matrix and more of the HCS anion participates in the doping process.

In agreement with the results presented in the Figures $3 b$ and $5 b$, the amount of PE incorporated into the PAni matrix reaches a maximum value when the PSS concentration in the work solution is about $20 \mathrm{mM}$.

This behavior is probably related to the fact that the polyelectrolyte is complete dissociated if the concentration of PE in solution is less than $20 \mathrm{mM}$. In that state, the negatively charged molecule facilitates the polymerization of the aniline either as a doping agent of the polymer, formed during 
the previous potential scanning, or through its adsorption. In this concentration range, the amount of polyelectrolyte incorporated into the PAni matrix is proportional to the concentration of PSS in solution.

On the other hand, if the PSS concentration in solution is higher than $20 \mathrm{mM}$, then the dissociation of the polyelectrolyte decreases and some of PE does not dissociate and remains as neutral molecules. These species neither can participate in improving polymerization performance nor be integrated into the PAni matrix.

Notably, the amount of undissociated molecules increases as the concentration of PSS in solution increases.

\subsection{Analysis of the Composite Deposits by Scanning Electron Microscopy}

To better understand the effect of the PSS concentration in solution on the morphology and the composition of the composites, micrographs were obtained using scanning electron microscopy (SEM), and the percentage sulfur content (\%S) by Environment Dispersing X ray (EDX) was obtained.

Figure 8 shows the images of PAni deposits obtained using different PSS concentrations in the working solution. These images clearly show the influence of PSS concentration during the formation of the polymer.
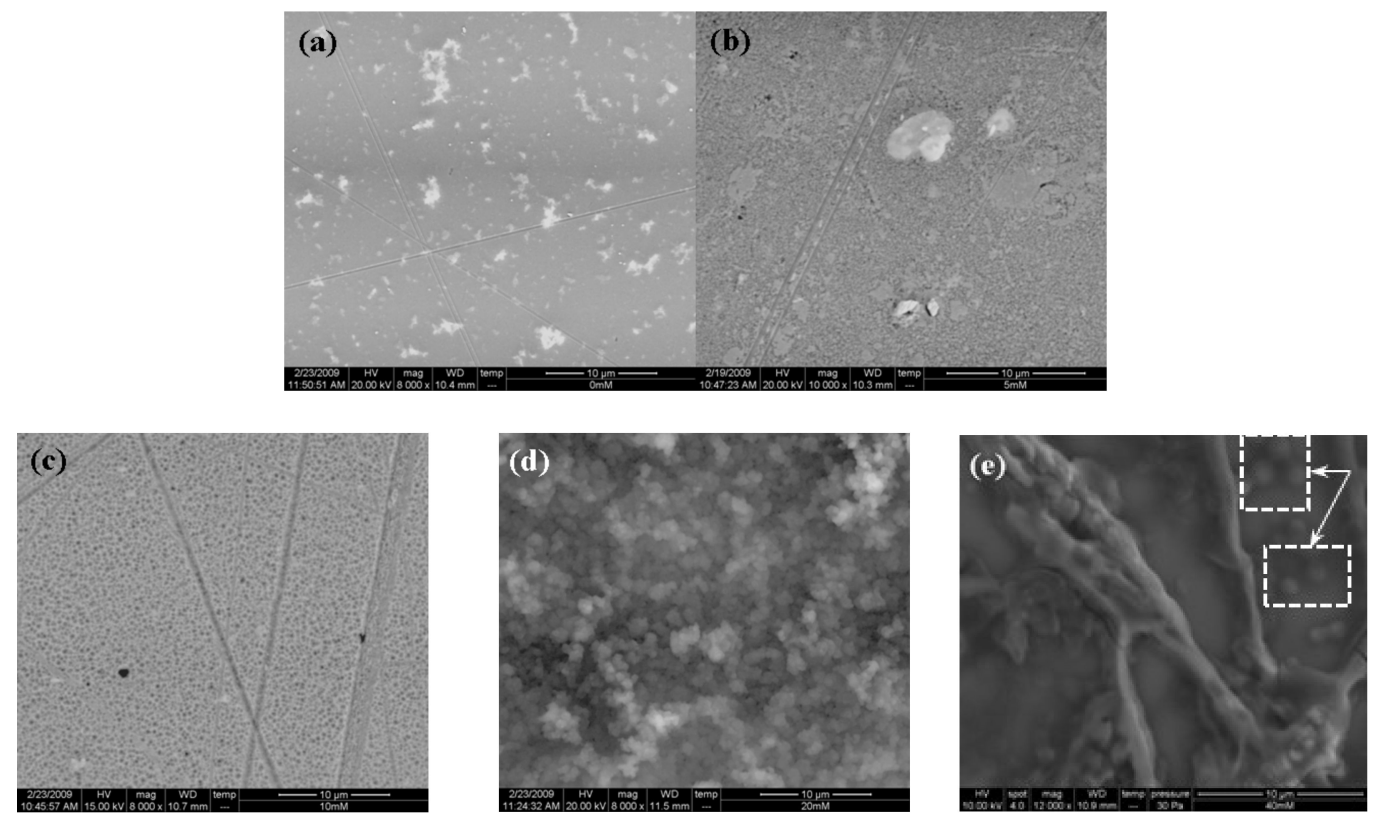

Figure 8. SEM images of the composite deposits obtained in presence of PSS at (a) 0, (b) 5, (c) 10, (d) 20, and (e) $40 \mathrm{mM}$. Scale: $10 \mu \mathrm{m}$.

Effectively, the PAni deposit obtained in absence of PSS (Figure 8a) shows a smooth surface that implies a fine porosity or a granular PAni film. The morphological characteristics of these films evolve with the PSS content in solution. As for the composite deposits obtained using 5 and $10 \mathrm{mM}$ of PSS, shown in Figure 8b,c, their surfaces are characterized by small pores that are homogeneously distributed. When the PSS concentration increases to $20 \mathrm{mM}$ (Figure $8 \mathrm{~d}$ ), then a surface composed of small well-defined grains is observed. Finally, the deposit obtained using a $40 \mathrm{mM}$ PSS concentration, shown in Figure 8e, shows large perfect spherical clusters (see for example marked section) that can combine to form both short and long filaments.

First, the deposit of PAni in the absence of PSS is granular, as has been reported when using sulfuric acid as a working solution [49].

Second, as already mentioned above, the pKa of PSSH (poly(4-styrenesulfonic acid)) is approximately $1.0[50,51]$. Thus, when the PSS concentration in the work solution is low, almost $50 \%$ of the sodium styrenesulfonate groups in PSSH are converted to electrically neutral styrenesulfonic 
acid groups. Due to the small number of negatively charged sites on the adsorbed polyelectrolyte in their salt form, polymerization of aniline resulted in PAni polymers that are loosely anchored on the polyelectrolyte template, which results in small PAni/PSS composite particles. The PAni in these deposits has small grains regularly distributed on the surface, as shown in Figure $8 b-d$. When the PSS concentration in solution increases, more styrenesulfonate groups on the polyelectrolyte remain in their salt form. Consequently, polymerization of aniline results in shorter PAni polymer chains that stick tighter on the polyelectrolyte, producing smaller PAni/PSS composite nanoparticles. These deposits are characterized by small grains that can increase in size and combine to form short and long filaments.

Accordingly, the polyelectrolyte must gradually integrate into the PAni deposits. Figure 9 shows the content of sulfur in the deposits (\%S) as a function of PSS concentration in work solution [52].

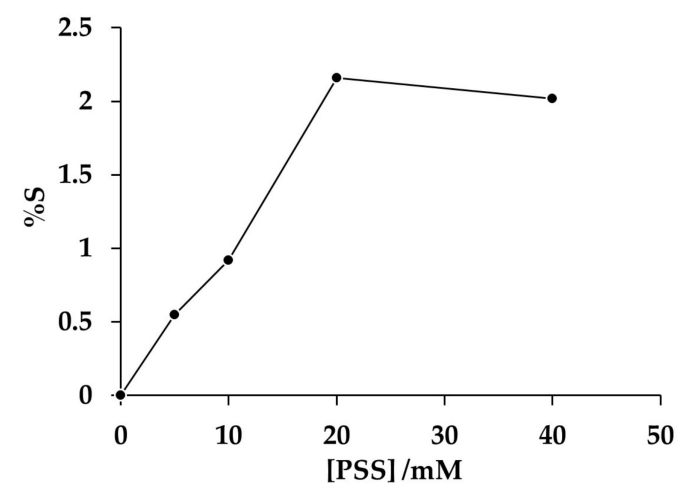

Figure 9. Percentage of content of sulfur in the PAni/PSS deposits (\%S) as a function of polyelectrolyte concentration in solution used to modify the commercial AFN membranes.

As can be seen, the amount of polyelectrolyte incorporated is actually proportional to the PSS concentration between 0 and $20 \mathrm{mM}$, while it reaches a maximum value when the PSS in solution is greater than $20 \mathrm{mM}$. If the PSS concentration in solution is higher than $20 \mathrm{mM}$, then \%S decreases slightly.

This behavior of the content of sulfur, $\%$, is the same as that observed with the amount adsorbed of PSS detected by EQCM (see Figure 4); therefore, the reasons for this should be the maximization of electrostatic repulsions between previously adsorbed polyelectrolyte molecules, as discussed above.

\subsection{Modifications of the Commercial Anion Exchange Membranes with PAni/PSS Composites}

To better understand whether the behavior of the results obtained in the previous sections extends to those obtained using commercial membranes, the membrane was modified with PAni in presence of different amounts of PSS in the working solution. Figure 10 shows the voltammetric responses obtained for the deposits on the membranes in $1 \mathrm{M} \mathrm{H}_{2} \mathrm{SO}_{4}$ without aniline.

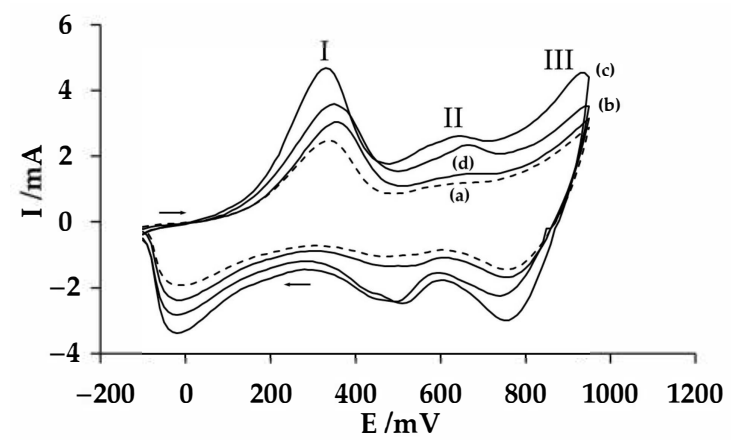

Figure 10. Voltammetric responses of the PAni deposited on the membranes with the following PSS concentrations in solution: (a) 0, (b) 5, (c) 20, and (d) $40 \mathrm{mM}$ of PSS in $1 \mathrm{M} \mathrm{H}_{2} \mathrm{SO}_{4} 1 \mathrm{M}$ at a $100 \mathrm{mV} / \mathrm{s}$ scan rate. 
First, in Figure 10, all the responses are observed to have three pairs of peaks, denoted I, II and III that are characteristic of the typical response of PAni in acidic solution [42,43].

Additionally, a more rigorous analysis shows that these responses follow a behavior similar to that described in Section 3.1. To appreciate this behavior, the peak current as a function of the PSS concentration in the work solution of the anodic peak I was found, as shown in Figure 11.

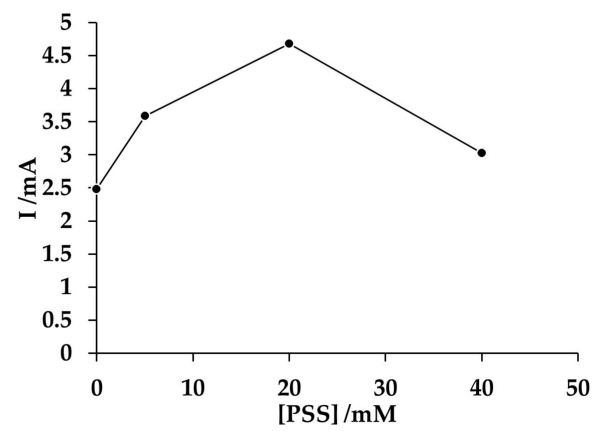

Figure 11. Plot of the anodic current peak (peak I, see Figure 10) as a function of the polyelectrolyte concentration in solution during the membrane modification processes.

Clearly, this curve exhibits the same behavior as that of the curve in Figure $1 \mathrm{~b}$ with an inflection point at $20 \mathrm{mM}$, which indicates that the PSS has the same effect on the PAni deposits obtained on the solid electrode as on the membrane. This implies not only that the electrochemical properties of the composite deposit, discussed in previous sections, are not affected by the membrane, but also that the transport properties of the membranes may be affected by these types of deposits.

For example, Figure 12 shows the transport numbers of $\mathrm{Cl}^{-}$obtained using these modified membranes.

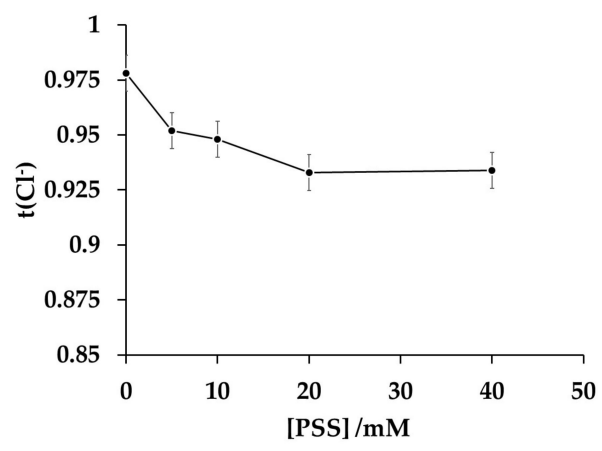

Figure 12. Transport number of $\mathrm{Cl}^{-}\left(\mathrm{t}\left(\mathrm{Cl}^{-}\right)\right)$as a function of the polyelectrolyte concentration in solution used to modify the commercial AFN membranes.

According to these data, the transport number of $\mathrm{Cl}^{-}$decreases by increasing the concentration of PSS between 0 and $20 \mathrm{mM}$. If the concentration of PSS is increased from 20 to 40, then the transport number of $\mathrm{Cl}^{-}$slightly increases. It is important to note the remarkable relationship between this curve and the amount of PE incorporated in the deposits of PAni shown by the Figure 9.

Effectively, the transport number of $\mathrm{Cl}^{-}$decreases due to the increase in the incorporation of $\mathrm{PE}$ into the PAni matrix when the PSS concentration in solution is between 0 and $20 \mathrm{mM}$. When even more PE is incorporated into the deposit when the PSS concentration increases, the Cl- anion will find increasing opposition to its passage through the membrane, because of the electrostatic repulsions between the PE and $\mathrm{Cl}^{-}$. Therefore, the transport number will decrease. In the case where the PSS concentration in solution is $40 \mathrm{mM}$, then the transport number increases slightly because of the small decrease in the amount of PSS incorporated into the PAni matrix. 


\section{Conclusions}

In this paper, the effect of the concentration of poly(sodium 4-styrene sulfonate) (PSS) in solution on the electropolymerization of polyaniline (PAni) in acid solution using a EQCM was analyzed for the first time. Then, the results obtained from first step are extended to the modification of a commercial anion exchange membrane with these PAni/PSS composites.

Importantly, when the PSS concentration in solution is between 0 to $20 \mathrm{mM}$, then the amount of PSS that incorporates into the PAni matrix was found to be directly proportional to its value in solution. For PSS concentrations in solution above $20 \mathrm{mM}$, the amount of polyelectrolyte incorporated into the PAni matrix was found to reach a practically constant value.

The use of the EQCM to analyze the effect of the incorporation of PSS into the PAni matrix showed that the polyelectrolyte acts in the following two ways:

(a) The polyelectrolyte stimulates the polymerization of the PAni if its concentration in solution is between 0 and $20 \mathrm{mM}$ by adsorbing onto the electrode surface and avoiding the diffusion towards the solution of the oligomers.

(b) By studying the doping-dedoping process, we found that the PSS incorporated into the PAni matrix could play an important role in neutralizing the excess positive charge in the doped polymer if a voluminous counterion such as the anion of HCS (camphorsulfonate) is in solution.

Finally, regarding the modification of a commercial anion exchange membrane with composite deposits, several results were found, which were in agreement with those obtained using the solid electrode. For example, the transport number of chloride decreases progressively (when the PSS concentration in solution is between 0 and $20 \mathrm{mM}$ ) to reach a practically constant value when a concentration of PSS that is greater than $20 \mathrm{mM}$ was used. This result shows that when the amount of PSS increases in the composite then the electrostatic repulsions with approaching anions are more intense, resulting in a smaller transport number.

Author Contributions: A.M.-R. and L.M.T.-R. conceived of and designed the experiments; M.R.-O. and J.G.Á.-R. performed the experiments; A.M.-R. and L.M.T.-R. analyzed the data; A.M.-R. wrote the paper. All authors have read and agreed to the published version of the manuscript.

Funding: This work was supported by CONACYT (CB 2008-01, 105875).

Conflicts of Interest: The authors declare no conflict of interest. The founding sponsors had no role in the design of the study; in the collection, analyses, or interpretation of data; in the writing of the manuscript, and in the decision to publish the results.

\section{References}

1. Van der Bruggen, B. Chemical Modification of Polyethersulfone Nanofiltration Membranes: A Review. J. Appl. Polym. 2009, 114, 630-642. [CrossRef]

2. Khan, M.A.; Arsalan, M.; Khan, M.R. Membrane Applications of Polyaniline based Nanocomposite Ion-exchanger and its Electrochemical Properties for Desalination. J. Membr. Sci. Technol. 2016, 6, 1.

3. Largier, T.D.; Wang, D.; Mueller, J.; Cornelius, C.J. Improving electrodialysis based water desalination using a sulfonated Diels-Alder poly(phenylene). J. Membr. Sci. 2017, 531, 103-110. [CrossRef]

4. Louati, I.; Guesmi, F.; Hannachi, C.; Hamrouni, B. Effect of ionic strength on the ion exchange equilibrium between AMX membrane and electrolyte solutions. Water Qual. Res. J. Can. 2016, 51, 60-68. [CrossRef]

5. Tan, S.; Laforgue, A.; Bélanger, D. Characterization of a Cation-Exchange/Polyaniline Composite Membrane. Langmuir 2003, 19, 744-751. [CrossRef]

6. Van der Bruggen, B.; Koninckx, A.; Vandecasteele, C. Separation of monovalent and divalent ions from aqueous solution by electrodialysis and nanofiltration. Water Res. 2004, 38, 1347-1353. [CrossRef]

7. Ran, J.; Wu, L.; He, Y.; Yang, Z.; Wang, Y.; Jiang, C.; Ge, L.; Bakangura, E.; Xu, T. Ion exchange membranes: New developments and applications. J. Membr. Sci. 2017, 522, 267-291. [CrossRef]

8. Lai, A.N.; Zhou, K.; Zhuo, Y.Z.; Zhang, Q.G.; Zhu, A.M.; Ye, M.L.; Liu, Q.L. Anion exchange membranes based on carbazole-containing polyolefin for direct methanol fuel cells. J. Membr. Sci. 2016, 497, 99-107. [CrossRef] 
9. Zhu, L.; Pan, J.; Wang, Y.; Han, J.; Zhuang, L.; Hickner, M.A. Multication Side Chain Anion Exchange Membranes. Macromolecules 2016, 49, 815-824. [CrossRef]

10. Bhadra, S.; Khastgir, D.; Singha, N.K.; Lee, J.H. Progress in preparation, processing and applications of polyaniline. Prog. Polym. Sci. 2009, 34, 783-810. [CrossRef]

11. Wang, H.; Lin, J.; Shen, Z.X. Polyaniline (PANi) based electrode materials for energy storage and conversion. J. Sci. 2016, 1, 225-255. [CrossRef]

12. Farrokhzad, H.; Moghbeli, M.R.; Van Gerven, T.; Van der Bruggen, B. Surface modification of composite ion exchange membranes by polyaniline. React. Funct. Polym. 2015, 86, 161-167. [CrossRef]

13. Shkirskaya, S.A.; Senchikhin, I.N.; Kononenko, N.A.; Roldugin, V.I. Effect of Polyaniline on the Stability of Electrotransport Characteristics and Thermochemical Properties of Sulfocationite Membranes with Different Polymer Matrices. Russ. J. Electrochem. 2017, 53, 78-85. [CrossRef]

14. Berezina, N.P.; Kubaisi, A.A.-R.; Alpatova, N.M.; Andreev, V.N.; Griga, E.I. Composite Polyaniline/MF-4SK Membranes: A Chemical Template Synthesis and the Sorption and Conduction Properties. Russ. J. Electrochem. 2004, 40, 286-293. [CrossRef]

15. Berezina, N.P.; Gnusin, N.P.; Demina, O.A.; Annikova, L.A. Effect of Polyaniline on the Current Passing through Structural Fragments of Ion-Exchange Sulfonic-Cationite Resins and Membranes. Russ. J. Electrochem. 2009, 45, 1226-1233. [CrossRef]

16. Compañ, V.; Riande, E.; Fernandez-Carretero, F.J.; Berezina, N.P.; Sytcheva, A.A.-R. Influence of polyaniline intercalations on the conductivity and permselectivity of perfluorinated cationexchange membranes. J. Membr. Sci. 2008, 318, 255-263. [CrossRef]

17. Schwenzer, B.; Kim, S.; Vijayakumar, M.; Yang, Z.; Liu, J. Correlation of structural differences between Nafion/polyaniline and Nafion/polypyrrole composite membranes and observed transport properties. J. Membr. Sci. 2011, 372, 11-19. [CrossRef]

18. Berezina, N.P.; Shkirskaya, S.A.; Kolechko, M.V.; Popova, O.V.; Senchikhin, I.N.; Roldugin, V.I. Barrier Effects of Polyaniline Layer in Surface Modified MF4SK/Polyaniline Membranes. Russ. J. Electrochem. 2011, 47, 995-1005. [CrossRef]

19. Berezina, N.P.; Kononenko, N.A.; Sytcheva, A.A.-R.; Loza, N.V.; Shkirskaya, S.A.; Hegman, N.; Pungor, A. Perfluorinated nanocomposite membranes modified by polyaniline: Electrotransport phenomena and morphology. Electrochim. Acta 2009, 54, 2342-2352. [CrossRef]

20. Nagarale, R.K.; Gohil, G.S.; Shahi, V.K.; Trivedi, G.S.; Rangarajan, R. Preparation and electrochemical characterization of cation- and anion-exchange/polyaniline composite membranes. J. Colloid Interface Sci. 2004, 277, 162-171. [CrossRef]

21. Baker, C.K.; Qiu, Y.-J.; Reynolds, J.R. Electrochemically-induced charge and mass transport in polypyrrole/poly(styrene sulfonate) molecular composites. J. Phys. Chem. 1991, 95, 4446-4452. [CrossRef]

22. Pickup, P.G. Electrochemistry of Electronically Conducting Polymer Films. In Modern Aspects of Electrochemistry; White, R.E., Bockris, J.O.M., Conway, B.E., Eds.; Kluwer/Plenum: New York, NY, USA, 1999; No. 33; pp. $549-597$.

23. Inzelt, G. Mechanism of charge transport in polymer-modified electrodes. In Electroanalytical Chemistry; Bard, A.J., Ed.; Marcel Dekker: New York, NY, USA, 1994; Volume 18, pp. 89-241.

24. Jang, J.; Ha, J.; Kim, K. Organic light-emitting diode with polyaniline-poly(styrene sulfonate) as a hole injection layer. Thin Solid Films 2008, 516, 3152-3156. [CrossRef]

25. Hyodo, K.; Omae, M.; Kagami, Y. Effect of molecular weight on the ion selective electrochemical polymerization of aniline. Electrochim. Acta 1991, 36, 357-360. [CrossRef]

26. Hyodo, K.; Nokazi, M. High ion selective electrochemical synthesis of polyaniline. Electrochim. Acta 1988, 33, 165-166. [CrossRef]

27. Hwang, J.H.; Yang, S.C. Morphological modification of polyaniline using polyelectrolyte template molecules. Synth. Met. 1989, 29, 271-276. [CrossRef]

28. Wang, J.; Jiang, M. Toward Genolelectronics: Nucleic Acid Doped Conducting Polymers. Langmuir 2000, 16, 2269-2274. [CrossRef]

29. Buttry, D.A.; Ward, M. Measurement of Interfacial Processes at Electrode Surfaces with the Electrochemical Quartz Crystal Microbalance. Chem. Rev. 1992, 92, 1355-1379. [CrossRef]

30. Ward, M. Principles and applications of the electrochemical quartz crystal microbalance. In Monographs in Electroanalytical Chemistry and Electrochemistry: Physical Electrochemistry, Principles, Methods, and Applications; Rubinstein, I., Ed.; Marcel Dekker: New York, NY, USA, 1995; pp. 293-338. 
31. Orata, D.; Buttry, D.A. Determination of ion populations and solvent content as functions of redox state and pH in polyaniline. J. Am. Chem. Soc. 1987, 109, 3574-3581. [CrossRef]

32. Ding, H.; Park, S.-M. Electrochemistry of conductive polymers XXVII. Effects of polystyrene sulfonate on electrochemical behavior of polyaniline. J. Electrochem. Soc. 2003, 150, E33-E38. [CrossRef]

33. Iyoda, T.; Ohtani, A.; Honda, K.; Shimidzu, T. Diaphragmatic Chemical Polymerization of Pyrrole in the Nafion Film. Macromolecules 1990, 23, 1971-1976. [CrossRef]

34. Shimidzu, T.; Ohtani, A.; Honda, K. Charge-controllable polypyrrole/polyelectrolyte composite membranes: Part II. Effect of incorporated anion size on the electrochemical oxidation-reduction process. J. Electroanal. Chem. Interfacial Electrochem. 1987, 224, 123-135. [CrossRef]

35. Shimidzu, T.; Ohtani, A.; Honda, K. Charge-controllable poly pyrrole/poly electrolyte composite membranes: Part III. Electrochemical deionization system constructed by anionexchangeable and cation-exchangeable polypyrrole electrodes. J. Electroanal. Chem. Interfacial Electrochem. 1998, 251, 323-337. [CrossRef]

36. Pile, D.L.; Zhang, Y.; Hillier, A.C. Electrochemically Modulated Permeability of Poly(aniline) and Composite Poly(aniline)-Poly(styrenesulfonate) Membranes. Langmuir 2006, 22, 5925-5931. [CrossRef]

37. ASTOM Corporation. Available online: http://www.astom-corp.jp/en/product/10.html (accessed on 8 October 2020).

38. Tongwen, X.; Weihua, Y. Fundamental studies of a new series of anion exchange membranes: Membrane preparation and characterization. J. Membr. Sci. 2001, 190, 159-166. [CrossRef]

39. Montes Rojas, A.; Olivares Maldonado, Y.; Torres Rodríguez, L.M. An easy method to modify the exchange membranes of electrodialysis with electrosynthetized polyaniline. J. Membr. Sci. 2007, 300, 2-5. [CrossRef]

40. Lteif, R.; Dammak, L.; Larchet, C.; Auclair, B. Détermination du nombre de transport d'un contreion dans une membrane échangeuse d'ions en utilisant la méthode de la pile de concentration. Eur. Polym. J. 2001, 37, 627-639. [CrossRef]

41. Robson Wright, M. An Introduction to Aqueous Electrolyte Solutions; John Wiley \& Sons Ltd.: Chichester, UK, 2007; p. 381.

42. Genies, E.M.; Tsintavis, C. Electrochemical behaviour, chronocoulometric and kinetic study of the redox mechanism of polyaniline deposits. J. Electroanal. Chem. 1986, 200, 127-145. [CrossRef]

43. Mazeikiene, R.; Malinauskas, A. Kinetic study of the electrochemical degradation of polyaniline. Synth. Met. 2001, 123, 349-354. [CrossRef]

44. Mathebe, N.G.R.; Morrin, A.; Owuoha, E.I. Electrochemistry and scanning electron microscopy of polyaniline/peroxidase-based biosensor. Talanta 2004, 64, 115-120. [CrossRef]

45. Prasad, K.R.; Munichandraiah, N. Potentiodynamic deposition of polyaniline on non-platinum metals and characterization. Synth. Met. 2001, 123, 459-468. [CrossRef]

46. Donjuan-Medrano, A.-L.; Montes-Rojas, A. Comparison of sensitivity constants of an electrochemical quartz crystal microbalance determined by potentiostatic deposition of $\mathrm{Tl}, \mathrm{Pb}, \mathrm{Ag}$ and $\mathrm{Cu}$ films. Curr. Top. Electrochem. 2012, 17, 75-85.

47. Bruckeinstein, S.; Swathirajam, S. Potential dependence of lead and silver underpotential coverages in acetonitrile using a piezoelectric crystal oscillator method. Electrochim. Acta 1985, 30, 851-855. [CrossRef]

48. Gabrielli, C.; Keddam, M.; Torresi, R. Calibration of the Electrochemical Quartz Crystal Microbalance. J. Electrochem. Soc. 1991, 138, 2657-2660. [CrossRef]

49. Mondal, S.K.; Prasad, K.R.; Munichandraiah, N. Analysis of electrochemical impedance of polyaniline films prepared by galvanostatic, potentiostatic and potentiodynamic methods. Synth. Met. 2005, 148, 275-286. [CrossRef]

50. Li, L.; Ferng, L.; Wei, Y.; Yang, C.; Ji, H.-F. Effects of acidity on the size of polyanilinepoly(sodium 4-styrenesulfonate) composite particles and the stability of corresponding colloids in water. J. Colloid Interface Sci. 2012, 381, 11-16. [CrossRef]

51. Kharlampieva, E.; Tsukruk, T.; Slocik, J.M.; Ko, H.; Poulsen, N.; Naik, R.R.; Kröger, N.; Tsukruk, V.V. Bioenabled Surface-Mediated Growth of Titania Nanoparticles. Adv. Mater. 2008, 20, 3274-3279. [CrossRef]

52. Garratt-Reed, A.J.; Bell, D.C. Energy-Dispersive X-ray Analysis in the Electron Microscope; BIOS Scientific Publishers Limited: Oxford, UK, 2003; Chapter 5.

Publisher's Note: MDPI stays neutral with regard to jurisdictional claims in published maps and institutional affiliations. 
(C) 2020 by the authors. Licensee MDPI, Basel, Switzerland. This article is an open access article distributed under the terms and conditions of the Creative Commons Attribution (CC BY) license (http://creativecommons.org/licenses/by/4.0/). 